\title{
Beating-heart, off-pump mitral valve repair by implantation of artificial chordae tendineae: An acute in vivo animal study
}

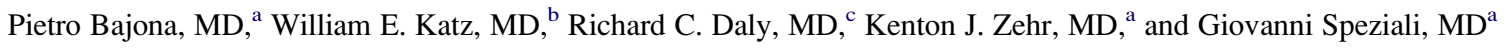

Objective: To evaluate the effectiveness of a new off-pump mitral valve repair technology in restoring valve competency in a porcine model of acute mitral regurgitation.

\begin{abstract}
Methods: Acute mitral regurgitation was induced in 6 anesthetized pigs by cutting anterior leaflet chordae. Artificial chordae were then transapically implanted on the prolapsing segment under epicardial echocardiographic guidance and secured outside the left ventricular apex. All intracardiac manipulations were performed off-pump, through a stab wound incision on the left ventricular apex.
\end{abstract}

Results: Cutting the anterior leaflet chordae caused an eccentric, posteriorly directed jet of mitral regurgitation that could be visualized by color Doppler sonography. Implantation of chordae through the left ventricular apex completely eliminated valve regurgitation in 4 animals and reduced regurgitation in 2 . Intraoperative measurement of artificial chordal tensions gave similar values to those reported for native chordae.

Conclusions: Off-pump, transapical implantation of artificial chordae between a prolapsing anterior mitral valve leaflet and the left ventricular apex was effective in reducing acutely induced mitral regurgitation. Long-term studies are planned to assess the stability in this animal model.

Video clip is available online.

One of the most frequent causes of severe nonischemic mitral regurgitation (MR) is mitral valve prolapse (MVP). The prevalence of MVP in the United States is estimated at 2\% to $3 \%$ and shows no difference in distribution between men and women. ${ }^{1}$ In recent years, the development of new surgical techniques has made mitral valve (MV) repair, rather than replacement, the procedure of choice for most MV diseases. ${ }^{2}$ Despite improvement in clinical outcomes, current repair procedures are not perfect and surgical procedures still require the patient to be supported by cardiopulmonary bypass. $^{3}$

Implantation of artificial chordae tendineae (ACTs) is a widely used technique for correction of both posterior and anterior leaflet prolapse. ${ }^{4}$

From the Division of Cardiothoracic Surgery, Heart, Lung and Esophageal Surgery Institute, ${ }^{\mathrm{a}}$ the Department of Cardiology, ${ }^{\mathrm{b}}$ University of Pittsburgh Medical Center, Pittsburgh, Pa, and the Division of Cardiovascular Surgery, Mayo Clinic and Foundation, ${ }^{\mathrm{c}}$ Rochester, Minn.

This study was financially supported by Division of Cardiothoracic Surgery-HLESI, University of Pittsburgh Medical Center funds.

Received for publication Aug 1, 2008; revisions received Aug 1, 2008; accepted for publication Sept 1, 2008.

Address for reprints: Giovanni Speziali, MD, University of Pittsburgh, Division of Cardiac Surgery-HLESI, 200 Lothrop St, Suite C-700, Pittsburgh, PA 15213

(E-mail: spezialig@upmc.edu).

J Thorac Cardiovasc Surg 2009;137:188-93

$0022-5223 / \$ 36.00$

Copyright (c) 2009 by The American Association for Thoracic Surgery

doi:10.1016/j.jtcvs.2008.09.004
The new MV repair technology described in this study is the direct result of previous acute and short-term in vivo animal studies* and it allows off-pump implantation of ACTs using a specially designed instrument inserted through the left ventricular (LV) apex into the LV cavity. ACTs are implanted between the prolapsing/flail portion of a leaflet and the LV apex (Video E1 and Figure 1) without cardiopulmonary bypass and can be adjusted intraoperatively under echocardiographic guidance. This technology was developed to explore the feasibility of a transapical approach to MV repair, with the following added benefits, which may reduce operative morbidity during MVP repair: (1) off-pump procedure; (2) may be performed through a small incision without full sternotomy; (3) the ability to intraoperatively assess, adjust, and reverse ACT implantation.

This study assesses the feasibility of the system and the acute echocardiographic and hemodynamic changes during the procedure.

\section{MATERIAL AND METHODS \\ Design}

The surgical tool for ACT implantation was composed of a handle, to manipulate and orient the device, and a rigid shaft with a sliding mechanism, to grab and securely hold the prolapsing leaflet segment. The rigid shaft contained the suture, a needle, and a fiberoptic visualization system. The suture was contained in a channel and formed a continuous loop. Another channel contained a harpoon-tipped needle (Figure 2),

\footnotetext{
* Speziali G, Bruce CJ, Gilman G, Potter DD, Daly RC. Totally Endoscopic Intracardiac Repairs on a Beating Heart. In: The ISMICS Conference, June 19-21, 2003, San Francisco, California, and Speziali G, Potter DD, Bruce CJ, Gilman G, Henke PS, Suddendorf SH, Timmons MJ, Daly RC. Endoscopic, Off-pump Mitral Valve Repair: Continued Development of a New Technique. In: The ISMICS Conference, June 19-21, 2004, London, United Kingdom.
} 


\section{Abbreviations and Acronyms \\ ACTs $=$ artificial chordae tendineae \\ $\mathrm{LV}=$ left ventricular \\ MR = mitral regurgitation \\ $\mathrm{MV}=$ mitral valve \\ $\mathrm{MVP}=$ mitral valve prolapse}

used to grab the suture and pull it through the MV leaflet to create a half hitch around the leaflet edge.

The fiberoptic visualization system consisted of four parallel channels, built into the instrument shaft, connected to a monitor. The fiberoptics were arranged around the needle channel in a manner such that the grasped MV leaflet was pulled against the fiberoptic extremities (Figure 3, A). When no valve tissue was grasped, the monitor showed four red dots because the fiberoptics were in direct contact with the blood (Figure 3,B). When the MV tissue was grasped, the dots turned white because the fiberoptics contacted tissue, indicating that the ACT insertion point would be at a depth of 3 to 4 $\mathrm{mm}$ from the leaflet edge allowing a sufficient line of coaptation. If the monitor showed four white dots, the "bite" on the MV leaflet was optimal (Figure $3, C$ ). If only the upper two dots turned white, the "bite" on the leaflet was too shallow. Real time echocardiographic guidance provided sufficient visual information for the device to capture the valve leaflets in the intended segment. The fiberoptic system confirmed an adequate "grasp" of the leaflet itself. Integration of the two visualization methods enabled successful and reproducible positioning the ACT in all animals.

\section{In Vivo Study}

This study was approved by the University of Pittsburgh's Institutional Animal Care and Use Committee, and all animals received humane care in accordance with the "Guide for the Care and Use of Laboratory Animals" (National Institutes of Health publication 85-23, revised 1985). Six Yucatan pigs (body weight, $88 \pm 12.2 \mathrm{~kg}$ ) were anesthetized with ketamine $(2.2 \mathrm{mg} / \mathrm{kg})$, telazol $(4.4 \mathrm{mg} / \mathrm{kg})$, and xylazine $(2.2 \mathrm{mg} / \mathrm{kg})$ and intubated.
Anesthesia was maintained with isoflurane (1\%-2\%). Lidocaine (100 $\mathrm{mg}$ ) was given to prevent arrhythmias. The heart was accessed through a median sternotomy. Heparin (300 units/kg) was administered intravenously. During the experiments, left atrial pressure, aortic pressure, left ventricular pressure, and central venous pressure were measured with $5 \mathrm{~F}$ catheters. The electrocardiogram was monitored. Epicardial 2-dimensional echocardiograms (HP SONOS 1500; Hewlett Packard, Andover, Mass) were obtained to follow the procedure and assess the final results.

A double pledget-supported purse-string suture was placed on the LV apex where a stab incision was made. MR was induced by cutting one or two major native chordae with a custom-made device under echocardiographic guidance. After the existence of MR had been confirmed, the surgical tool for ACT implantation was transapically inserted into the LV chamber (Figure 1). The prolapsing segment of the MV was grasped under direct fiberoptic visualization. One or more 5- expanded polytetrafluoroethylene sutures (Gore-Tex; W.L. Gore \& Associates, Inc, Flagstaff, Ariz) were secured to the free edge of the middle scallop of the anterior leaflet, in a position adjacent to the insertion point of the major strut chordae, which were cut (Figure 1,A). An accuracy of $2 \mathrm{~mm}$ or less was commonly achieved. After the new ACT was positioned, another loop was placed around the first one so that if the ACT was malpositioned, it could be simply retrieved by pulling the second suture, which remained outside the heart. The lengths of the newly implanted ACTs were adjusted manually and their function was assessed in real time by observing reduction or disappearance of MR by color Doppler echocardiogram (Figure 4, A and $B$ ). The procedure was repeated until the echocardiogram showed no residual MR or reduced MR.

The tension of each implanted ACT was then immediately measured with a digital tensiometer (TX-Series; Tensitron, Longmont, Colo) connected with a USB interface (1208FS; Measurements Computing, Norton, Mass) to the computer for data acquisition (Labview 7.1 software; National Instruments, Austin, Tex) and compared with the LV pressure during several cardiac cycles. The ACTs were secured outside the heart apex and hemostasis was achieved by tying the purse-string suture around the incision (Figure 1, B).

At the end of the experiment, each animal was monitored for at least 45 minutes and then humanely killed by intravenous administration of potassium chloride $(10 \mathrm{mEq} / \mathrm{kg})$. The heart was harvested and the $\mathrm{LV}$ opened

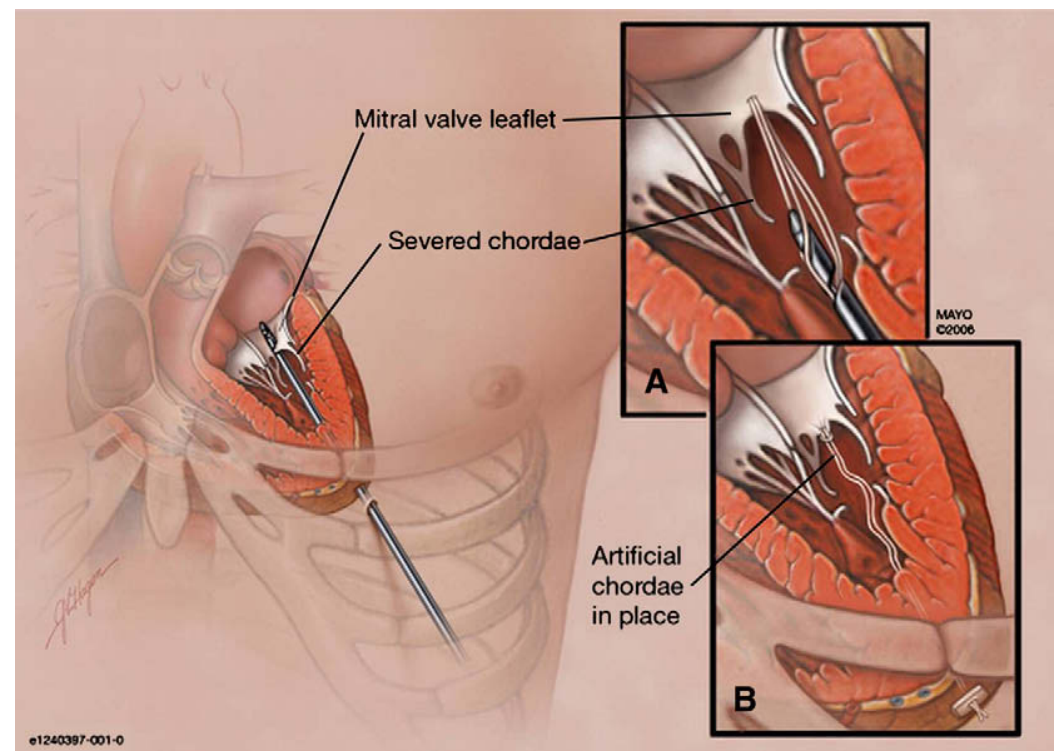

FIGURE 1. Schematic drawing of the surgical technique. A, The instrument is inserted in the LV cavity and new ACT is implanted on the MV leaflet. B, ACT in place and secured outside the LV apex. 


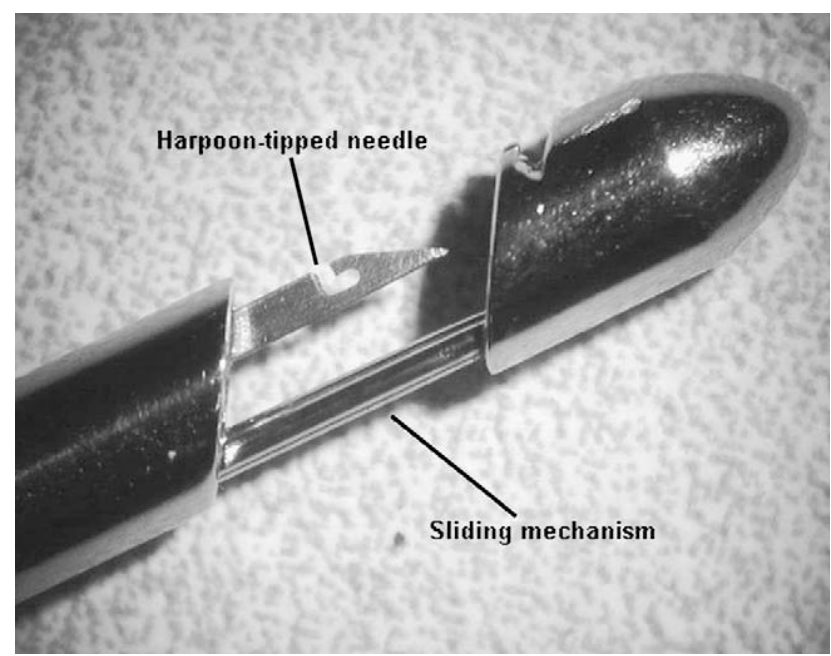

FIGURE 2. The open tip of the instrument with the sliding mechanism and the harpoon-tipped needle. to inspect both the ACT implantation site and the LV apex where the instrument was inserted.

\section{Statistical Analysis}

Hemodynamic data of the continuous variables were summarized and reported as median and interquartile range. The Wilcoxon signed rank test, a nonparametric equivalent of the paired $t$ test, was used to compare preimplant and postimplant data. SPSS version 15.0 software (SPSS Inc, Chicago, Ill) was used.

\section{RESULTS}

All the experiments were successfully conducted offpump. No bleeding or tears were observed at the site of instrument insertion. In all cases, MR could be detected by color Doppler echocardiogram when one or two major strut chordae of the MV anterior leaflet were cut. Up to 3 pairs of ACTs per animal were successfully implanted without damaging the valvular or subvalvular apparatus. In all cases, there was no need to retrieve the newly implanted ACT owing to malpositioning. Postoperative echocardiography showed no residual MR in 4 cases. In
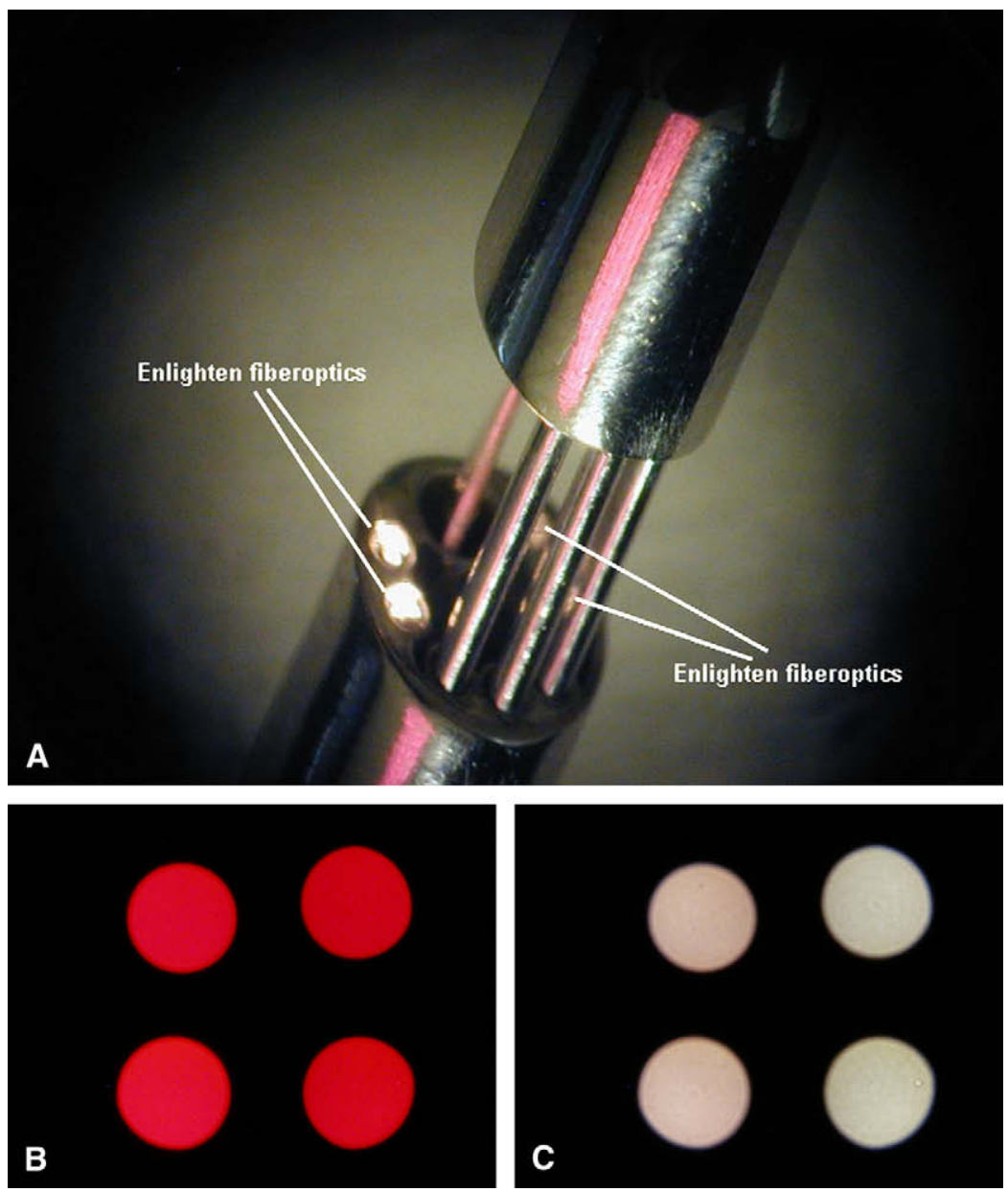

FIGURE 3. Instrument and fiberoptics. A, Opened tip of the instrument with enlighten fiberoptics. B, No valve tissue grasped. Four red dots resulted from the direct contact of the fiberoptics with the blood. C, MV tissue grasped. The fiberoptics contacting the tissue turned white. 

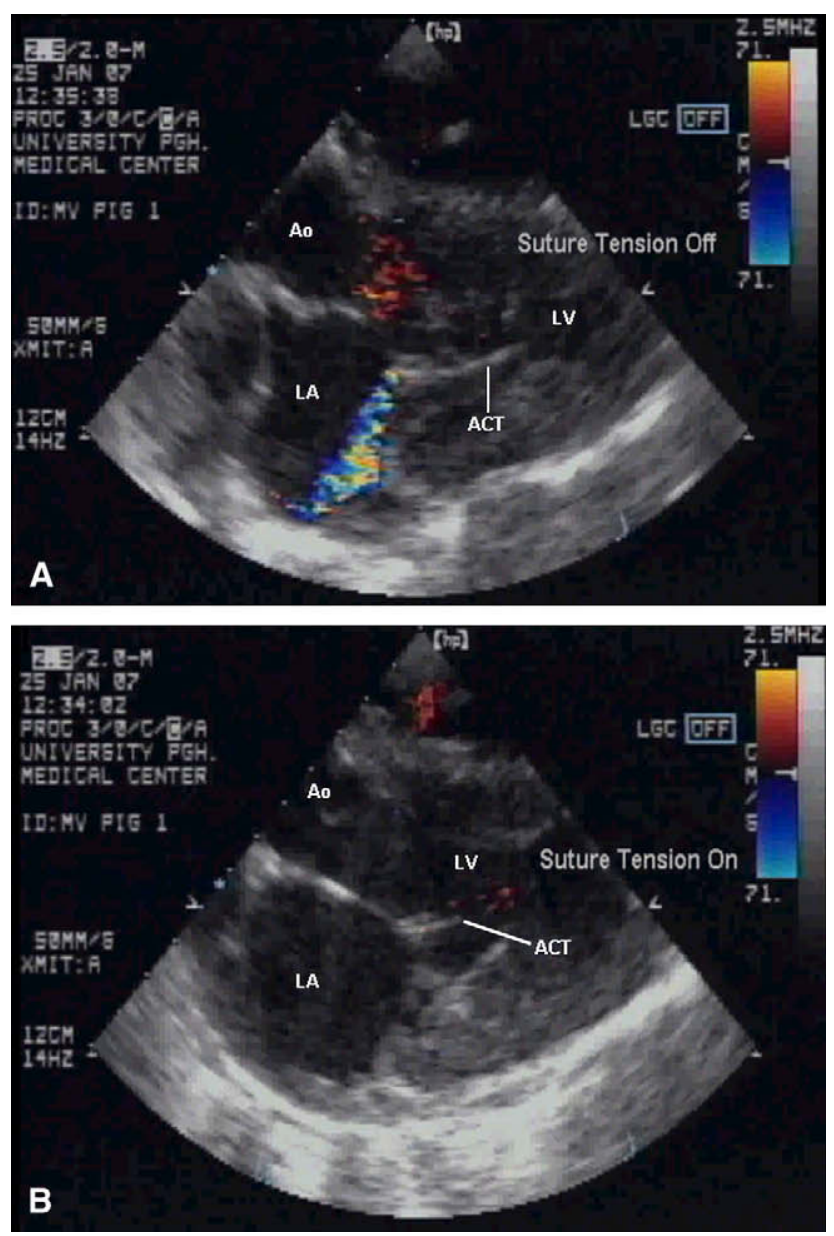

FIGURE 4. ACTs tensioning. A, Neoimplanted, nontensioned ACTs with MR. B, ACT length judged in real time by observing reduction or disappearance of MR with color Doppler echocardiogram. Ao, Aorta; $L A$, left atrium; $L V$, left ventricle; $A C T$, artificial chordae tendineae.

the remaining 2 cases, minimal MR was detected. Figure 5 shows the highlights of the procedure from a typical case. An eccentric jet was demonstrated by color Doppler echocardiography after cutting the native chordae (Figure 5, $A)$. The instrument was inserted into the $\mathrm{LV}$ chamber and grabbed the MV anterior leaflet (Figure 5, B). The suture was deployed and the instrument withdrawn from the LV cavity (Figure 5, C). After appropriate tensioning of the newly implanted ACT, MR disappeared (Figure 5, $D)$. During the operation, we used echocardiography to immediately assess the result and determine the correct tension to prevent MR (Figure 4). The mean implantation time for each ACT was $5 \pm 1.51$ minutes.

Hemodynamic data are shown in Table 1. On the basis of the $P$ value, the differences between before and after implantation in heart rate and mean aortic pressure could be due to chance $(P>.2)$. However, the differences between before and after implantation in systolic LV pressure, mean left atrial pressure, and mean central venous pressure values are statistically significant.

The numerical relationship between ACT tension (in Newtons, N) and LV pressure averaged 0.95 (range 0.71.1). Chordal tension measurements were of the same order of magnitude as those measured in native MV chordae ${ }^{5,6}$ and in ACTs in an in vitro simulation. ${ }^{7}$ Necroscopic inspection of both MV leaflets at the ACT insertion point and subvalvular apparatus did not show any anatomic abnormality or laceration (Figure 6, $A$ and $B$ ).

\section{DISCUSSION}

Since 1985, expanded polytetrafluoroethylene ACTs have been used for MVP repair. ${ }^{8}$ ACTs in MV positions do not shrink or break and become covered by an intimal tissue like native chordae. ${ }^{9}$ According to Phillips and colleagues, ${ }^{10}$ chordal replacement has superior outcomes after a long-term follow-up than chordal shortening and is relatively simple and reproducible. The present study investigated the feasibility of a new technology for MV repair by ACT implantation. In this animal model, transapical implantation of ACTs corrected surgically induced acute MR. In all animals, the experiments were performed off-pump. All intracardiac manipulations of the instrument and deployment of the ACTs were monitored through real-time echocardiography.

The newly implanted ACTs were subjected to the same ranges of tension as those of native chordae measured in previous studies. ${ }^{5-7}$ Thus, even when the ACTs are implanted and secured with different orientation from that of native chordae, they are subjected to physiologic tension levels and do not interfere with the MV subvalvular apparatus. Therefore, the LV apex appears to be a suitable location to anchor transapically implanted ACTs.

Indications for this new surgical treatment should focus primarily on patients with MVP who have redundant leaflet structure and motion, with MR attributed mainly to the protrusion of the leaflet tissue into the left atrial chamber during systole resulting in lack of leaflet coaptation and MR characterized by an eccentric jet. In fact, the device has been used to address MR in 3 patients, who are currently under evaluation for an appropriate follow-up period..$^{\dagger}$ More important, this device is an important step in evolving the technology for hybrid procedures in mitral valve repair. The device is not intended to treat MR arising from ischemic or dilated cardiomyopathy pathology.

\footnotetext{
${ }^{\dagger}$ Speziali G, Bruce CJ, Ricci D, Daly RC. Off-Pump Placement of Artificial Chordae Tendinae Corrects Mitral Regurgitation: Early Clinical Experience. In The ISMICS Conference, June 6-9, 2007, Rome, Italy, and Speziali G. Transapical Chordae Replacement. In The EACTS Conference, September 15-19, 2007, Geneva, Switzerland
} 

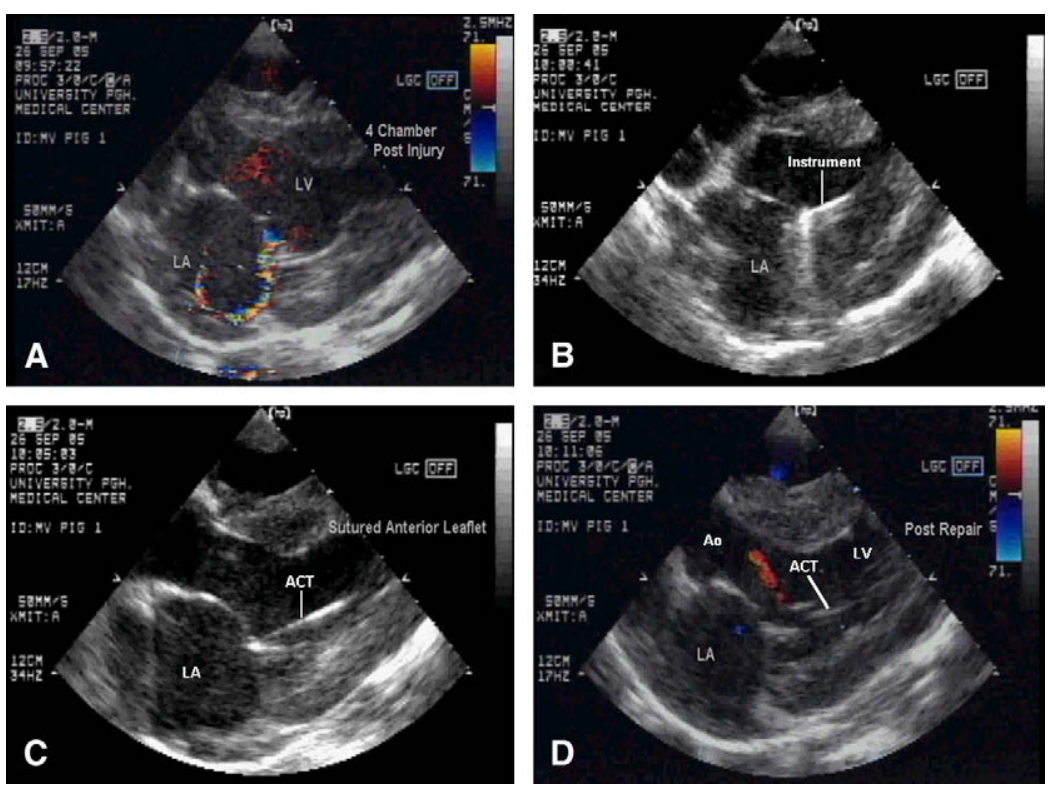

FIGURE 5. Surgical procedure highlights. A, MV eccentric jet is demonstrated by color Doppler sonography after cutting native chordae. B, Instrument ws inserted in the LV and grabbed the MV anterior leaflet. C, ACT in place after instrument withdrawal. D, Final result with no residual MR after ACT tensioning. Ao, Aorta; $L A$, left atrium; $L V$, left ventricle; $A C T$, artificial chordae tendineae.

\section{Study Limitations}

In this study, MR was induced by cutting one or two major native chordae on the anterior leaflet of an otherwise normal MV. Annular dilatation was not present, and the valve leaflets were thin and structurally normal. The MV chordal injury caused an eccentric, posteriorly directed jet of MR that could be visualized by color Doppler sonography. Assessing severity of eccentric MR by color Doppler sonometry is limited inasmuch as the jet area can underestimate the severity of the MR. In addition, more quantitative methods such as measuring the vena contracta or the proximal isovelocity surface area method are limited for this type of MR. Despite these limitations, epicardial echocardiography was able to show the mitral injury with a flail segment, color Doppler

TABLE 1. Hemodynamic data

\begin{tabular}{lccc}
\hline & $\begin{array}{c}\text { Preimplant } \\
\text { data,* } \\
\text { median } \\
\text { (IQR) }\end{array}$ & $\begin{array}{c}\text { Postimplant } \\
\text { data, } \\
\text { median } \\
\text { (IQR) }\end{array}$ & $\begin{array}{c}\text { P value } \\
\text { (Wilcoxon } \\
\text { signed rank } \\
\text { test) }\end{array}$ \\
\hline HR (beats/min) & $73.5(6.75)$ & $69.0(9.75)$ & .345 \\
AoPm (mm Hg) & $78.5(32.5)$ & $85.0(35.0)$ & .292 \\
LVPsys (mm Hg) & $92.0(16.0)$ & $95.0(12.0)$ & .042 \\
LAPm (mm Hg) & $17.0(3.0)$ & $15.0(3.0)$ & .039 \\
CVPm (mm Hg) & $11.0(3.0)$ & $9.0(2.75)$ & .041 \\
\hline
\end{tabular}

$A o P m$, Mean aortic pressure; $C V P m$, mean central venous pressure; $H R$, heart rate; $I Q R$, interquartile range; $L A P m$, mean left atrial pressure; $L V P s y s$, systolic left ventricular pressure. *Preimplant data were collected after mitral regurgitation was induced. sonography of the resultant MR, and the repair of the mitral leaflet with resolution of the MR.

This study was designed as a preliminary evaluation of a new technology that allows implantation of ACTs through the LV apex. Because the anchorage of the chordae to the apex could lead to changes in the native anatomy, such as the subvalvular apparatus and LV geometry, a detailed longer-term study on postoperative performance and remodeling is currently being performed. Our preliminary results suggest no changes on short-term follow-up ( $<1$ month) (Speziali G, Bajona P. Endoscopic, Off-Pump Mitral Valve Repair: A LongTerm Study; unpublished results). Further evaluation in a long-term survival model will be performed to explore both the potential and the contraindications of this new technique and to assess the stability of the ACT connection to the MV leaflets.

\section{CONCLUSIONS}

From the present study, we can conclude that off-pump ACT implantation from the LV apex is a feasible and reproducible procedure. In all cases, ACTs were successfully implanted with a specially designed surgical instrument. This innovative surgical procedure reduced or eliminated MR and the LV apex was demonstrated to be a suitable anchoring spot for newly implanted ACTs.

We thank Dr Shannon Wyszomierski for her assistance in editing this article and Mrs Sujatha Raghu, MBBS, MPH, for the statistical analysis review. 

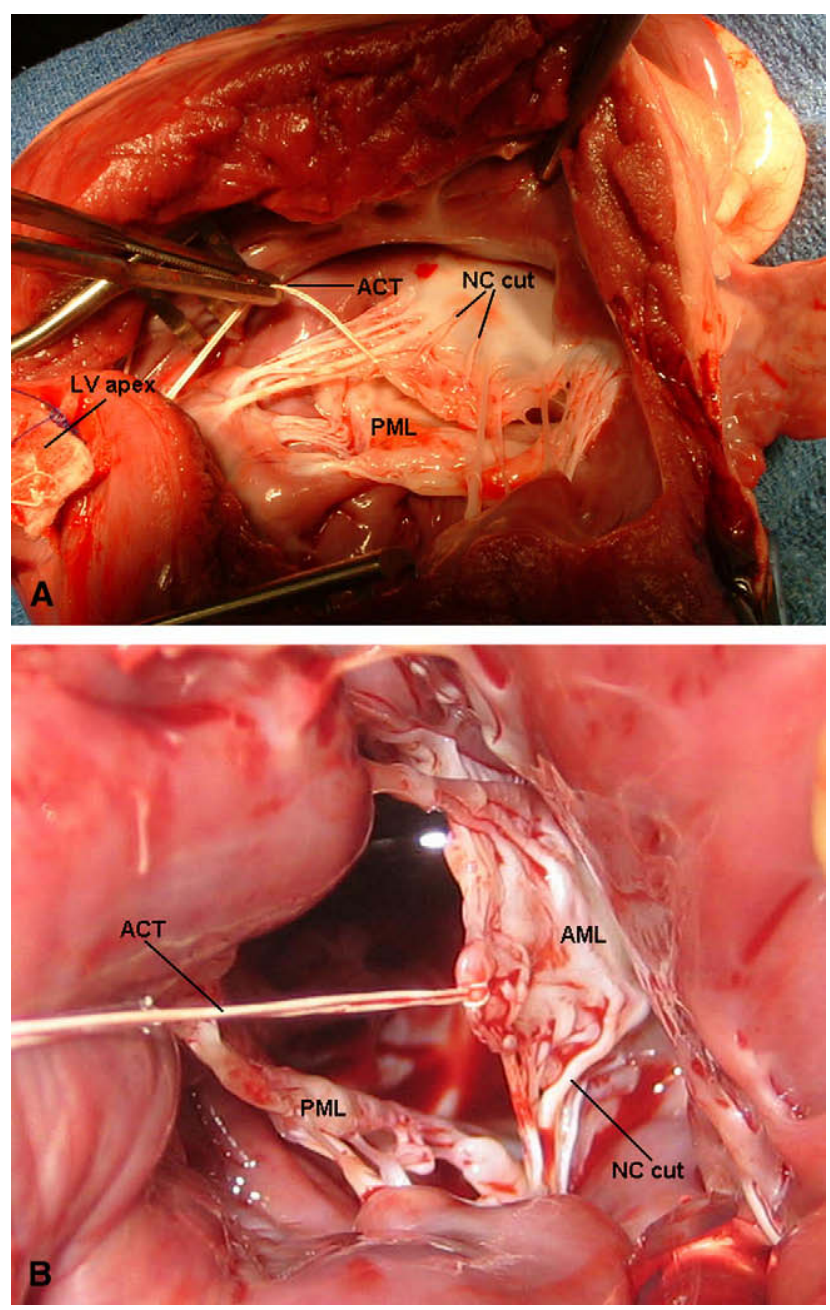

FIGURE 6. Postoperative inspection of valvular and subvalvular apparatus and newly implanted ACTs. A, Open view of the LV with two native chordae cut, an implanted ACT and LV apex with pledget-supported purse-string suture, and ACT anchorage. B, LV apical view of the MV with one native chordae cut and an implanted ACT. NC cut, Native chordae cut; $A C T$, artificial chordae tendinae; $P M L$, posterior mitral valve leaflet; $A M L$, anterior mitral valve leaflet; $L V$ apex, left ventricular apex.

\section{References}

1. Freed LA, Levy D, Levine RA, Larson MG, Evans JC, Fuller DL, et al. Prevalence and clinical outcome of mitral-valve prolapse. N Engl J Med. 1999;341:1-7.

2. Hayek E, Gring CN, Griffin BP. Mitral valve prolapse. Lancet. 2005;365:507-18. Review.

3. Suri RM, Schaff HV, Dearani JA, Sundt TM 3rd, Daly RC, Mullany CJ, et al Recurrent mitral regurgitation after repair: should the mitral valve be re-repaired? J Thorac Cardiovasc Surg. 2006;132:1390-7.

4. David T, Ivanov J, Armstrong S, Christie D, Rakowski H. A comparison of outcomes of mitral valve repair for degenerative disease with posterior, anterior, and bileaflet prolapse. J Thorac Cardiovasc Surg. 2005;130:1242-9.

5. Nielsen SL, Soerensen DD, Libergren P, Yoganathan AP, Nygaard H. Miniature C-shaped transducers for chordae tendineae force measurements. Ann Biomed Eng. 2004;32:1050-7.

6. Jimenez JH, Soerensen DD, He Z, Ritchie J, Yoganathan AP. Mitral valve function and chordal force distribution using a flexible annulus model: an in vitro study. Ann Biomed Eng. 2005;33:557-66.

7. Bajona P, Zehr KJ, Liao J, Speziali G. Tension measurement of artificial chordae tendineae implanted between the anterior mitral valve leaflet and the left ventricular apex: an in vitro study. Innovations. 2008;3:33-7.

8. David TE, Omran A, Armstrong S, Sun Z, Ivanov J. Long-term results of mitral valve repair for myxomatous disease with and without chordal replacement with expanded polytetrafluoroethylene sutures. J Thorac Cardiovasc Surg. 1998;115: 1279-85; discussion 1285-6.

9. David TE. Artificial chordae. Semin Thorac Cardiovasc Surg. 2004;16:161-8.

10. Phillips MR, Daly RC, Schaff HV, Dearani JA, Mullany CJ, Orszulak TA. Repair of anterior leaflet mitral valve prolapse: chordal replacement versus chordal shortening. Ann Thorac Surg. 2000;69:25-9. 